\title{
Mobile collaborative learning e o ensino de Ciências em diferentes contextos educacionais
}

\author{
Mobile collaborative learning and the teaching of Sciences in \\ different educational contexts
}

\section{Aprendizaje colaborativo móvil y la enseñanza de Ciencias en diferentes contextos educacionales}

\author{
Karla Angélica Silua do Nascimento' \\ Centro Universitário Christus - Unichristus, Professora \\ https://orcid.org/0000-0001-6103-2397 \\ https://lattes.cnpq.br/5267121220942302
}

José Aires de Castro Filho²

Universidade Federal do Ceará, Professor titular; Grupo de Pesquisa e Produção em Ambientes Interativos e Objetos de Aprendizagem, Líder

https://orcid.org/0000-0003-4611-0961

https://lattes.cnpq.br/1001172700194924

Resumo: 0 estudo mostra como as tecnologias móveis auxiliaram as aulas de Ciências, articulando conteúdo curricular e situações reais vividas na comunidade. Optou-se por uma abordagem qualitativa com o emprego da pesquisa-ação, envolvendo o trabalho colaborativo de uma professora interessada em contribuir com a resolução de preocupações relacionadas ao uso dessas tecnologias no contexto escolar. As entrevistas, o diário de campo e as observações das aulas foram analisadas e codificadas. Os resultados indicam que os elementos que subsidiam a Mobile Collaborative Learning, a partir da prática docente apoiada por dispositivos móveis, reconhecem a importância docente como mediador, envolvendo os alunos nas discussões sobre os temas estudados em diferentes contextos de aprendizagem. Para que essas tecnologias se integrem às atividades escolares é preciso tornar o currículo mais flexível, tanto ao planejamento quanto à execução, assim repensar políticas públicas que incentivem o uso desses dispositivos na escola, especialmente aqueles de uso próprio dos estudantes. Palavras-chave: Mobile Learning. Prática Docente. Dispositivos Móveis. Formação Docente.

Doutora em Educação Brasileira pela Universidade Federal do Ceará; Mestra em Educação pela Universidade Estadual do Ceará; karla.asn@gmail.com

2 Doutor em Mathematics Education pela University Of Texas At Austin; Mestre em Psicologia Cognitiva pela Universidade Federal de Pernambuco; aires@virtual.ufc.br 
Abstract: The study shows how mobile technologies have helped science classes, articulating curricular content and real situations experienced in the community. We chose a qualitative approach with the use of action research, involving the collaborative work of a teacher interested in contributing to the resolution of concerns related to the use of these technologies in the school context. Interviews, field diary and class observations were analyzed and coded. The results indicate that the elements that subsidize Mobile Collaborative Learning, based on the teaching practice supported by mobile devices, recognize the importance of teaching as mediator, involving the students in the discussions about the subjects studied in different learning contexts. For these technologies to be integrated into school activities, it is necessary to make the curriculum more flexible, both in planning and execution, thus rethinking public policies that encourage the use of these devices in school, especially those for students' own use.

Keywords: Mobilie Learning. Teaching Practice. Mobile devices. Teacher training.

Resumen: El estudio muestra cómo las tecnologías móviles ayudaron a las clases de Ciencias, articulando contenido curricular y situaciones reales vividas en la comunidad. Se optó por un abordaje cualitativo con el empleo de la investigación-acción, involucrando el trabajo colaborativo de una profesora interesada en contribuir con la resolución de preocupaciones relacionadas al uso de esas tecnologías en el contexto escolar. Las entrevistas, el diario de campo y las observaciones de clase fueron analizadas y codificadas. Los resultados indican que los elementos que subsidian a Mobile Collaborative Learning, a partir de la práctica docente apoyada por dispositivos móviles, reconocen la importancia docente como mediador, involucrando a los alumnos en las discusiones sobre los temas estudiados en diferentes contextos de aprendizaje. Para que esas tecnologías se integren a las actividades escolares es necesario que el currículo sea más flexible, tanto a la planificación y ejecución, repensar políticas públicas que incentiven el uso de esos dispositivos en la escuela, especialmente aquellos de uso propio de los estudiantes.

Palabras clave: Aprendizaje móvil. Práctica Docente. Dispositivos Móviles. Formación docente.

Recebido em 4 de setembro de 2019 Aceito em 7 de novembro 2019

Publicado em 19 de junho de 2020

\section{INTRODUÇÃO}

Os dispositivos móveis (notebook, netbook, tablet e smartphone) possuem sistemas interativos baseados na Web e redes de comunicação móveis (3G/4G), possibilitando mecanismos para comunicação e troca de informações. 
A potencialidade de integração dessas tecnologias com outras atividades, materiais e ambientes, cuja produção do conhecimento pode acontecer de forma colaborativa, possibilita a múltipla autoria e o compartilhamento de recursos fora dos limites de qualquer instituição educacional (FANTIN, 2017; FERREIRA; MUNIZ; OLIVEIRA JÚNIOR, 2018). Nesse sentido, como essas tecnologias móveis podem apoiar professores e estudantes na produção colaborativa de conhecimentos? Esse é um problema recorrente ao desafio que todas as instituições educacionais estão enfrentando desde a chegada desses recursos.

Ainda há moderadamente pouca compreensão acerca das formas como as tecnologias móveis podem ser usadas para auxiliar às atividades colaborativas aula. Hsu e Ching (2013) recomendam que a mobilidade destes dispositivos possibilite o trabalho colaborativo entre estudantes, a fim de estabelecer o movimento e interação com outros em ambientes diferentes, ao invés de limitar a atividade com um parceiro alocado em um desktop dentro de um laboratório. Além disso, reforçam a necessidade de pesquisas que investiguem como promover a colaboração e interação através de aplicações móveis disponiveis na Web que poderiam ser utilizadas na educação.

0 acesso à informação não está mais limitado a um computador desktop, pois se estendeu também às tecnologias móveis, o que originou uma área de estudos chamada de mobile learning ou m-learning, cuja tradução literal é aprendizagem móvel. 0 m-learning aproveita as potencialidades dos dispositivos móveis que oportunizam o ensino e a aprendizagem por meio de diferentes contextos, espaços e tempos. Sua definição e características são analisadas por estudos focados na mobilidade do aluno, outros na aprendizagem em diferentes contextos (ALMEIDA; VALENTE, 2014; WU et al., 2012; SHARPLES; TAYLOR; VAVOULA, 2010) e outros ainda no desenvolvimento de aplicações de aprendizagem móvel sustentadas por diferentes teorias de aprendizagem (MEHDIPOUR; ZEREHKAFI, 2013; LARU, NÄYKKI, JÄRVELÄ, 2015).

Apesar disso, esses autores focam, comumente, na utilização de dispositivos móveis na aprendizagem em diferentes contextos e no desenvolvimento de aplicações móveis. Porém, não exploram a produção colaborativa facilitada por esses recursos, auxiliando os conteúdos curriculares trabalhados em contextos escolares.

Diante do exposto, este estudo teve como objetivo compreender como os dispositivos móveis podem auxiliar a prática docente, durante a realização de um projeto pedagógico na e além da sala de aula. Neste artigo tem relevância, pois aborda a Mobile Collaborative Learning (MC-Learning) ou Aprendizagem Colaborativa Móvel que se refere ao uso de tecnologias móveis (tablet, netbook, smartphones) em experiências pedagógicas colaborativas que extrapolam a sala de aula, com propósitos do ensino formal. Além disso, apresenta consonância com a UNESCO (2014) que recomenda também o uso de smartphones na escola. 


\section{MOBILE COLLABORATIUE LEARNING E O ENSINO DE CIÊNCIAS}

0 acesso à internet expandiu as possibilidades de interação e, por conseguinte de colaboração entre as pessoas. Laru, Näykki e Jäverlä (2015), Berribili e Mill (2018), Fonseca (2019), reforçam que a interação entre as atividades individuais e colaborativas estão estabelecendo novos desafios para apoiar o ensino. Para isso, é necessário pensar como os docentes podem integrar estas tecnologias aos métodos mais ou menos tradicionais de ensino e currículo.

Essas tecnologias podem propiciar diferentes formas de interação viabilizando o saber coletivo, visto que a utilização de dispositivos móveis em ambientes que suscitem aprendizagem colaborativa pode fazer com que o aluno assuma uma postura compartilhada, através de uma comunicação, cujo envolvimento com as atividades se dá na produção, reflexão e tomadas de decisões coletivas (ARAÚJO; ESTEVES, 2017; FERNANDES, 2016). 0 estudante necessita compreender e ser compreendido pelo outro, para que os conflitos e os diferentes níveis de desenvolvimento colaborem para o cumprimento dos objetivos comuns do grupo.

Nesse sentido, a aprendizagem móvel e práticas colaborativas na educação aplicada como modelo de reflexão pedagógica podem ajudar o professor e seus estudantes a tomarem consciência de suas práticas e tentarem modificá-las.

As práticas colaborativas auxiliadas pelas características da aprendizagem móvel, derivam de diferentes níveis de interação e podem variar de um indivíduo para outro. Estas práticas exigem, dos envolvidos, troca de experiências, reflexão, decisões, compartilhamento que não admitem um único autor. A solução do problema é fruto do envolvimento de todos durante o seu desenvolvimento, porque o processo de aprendizagem é natural e gradativo. (PEREIRA; RIBERIR0, 2017). Em algumas situações, os sujeitos podem aprender uns com os outros sem mesmo se darem conta deste processo.

Diante do que foi posto, entende-se que a aprendizagem colaborativa, por meio de tecnologias móveis, se apresenta como instrumento mediador que auxilia a atividade cognitiva do aluno. No entanto, é necessário que o professor analise o uso desse método com o intuito de proporcionar melhor aprendizagem, selecione recursos que venham a facilitar a troca de informações e a produção coletiva do conhecimento, tornando-as mais naturais e criativas.

Zurita e Nussbaum (2007) ressaltam propósitos de uma outra abordagem chamada de Mobile Computer Supported Collaborative Learning (MCSCL) que gerenciam e incentivam tarefas de: organização de informações, colaboração em grupos, monitoramento 
do progresso em tempo real no que diz respeito aos objetivos e controle da interação de aprendizagem, negociação, coordenação e comunicação, desenvolvidas em uma sala de aula ou em qualquer outro espaço da escola.

No entanto, a representação da MCSCL exposta traz algumas contradições. Os autores exprimem a importância de usar os handhelds em qualquer lugar e hora, situação que não foi analisada pelos pesquisadores. Verifica-se, portanto, neste estudo que o termo Mobile Collaborative Learning, conecta aspectos primordiais da aprendizagem colaborativa com as expectativas da aprendizagem móvel na educação. A mobilidade e a colaboração podem aprimorar os processos de ensino e de aprendizagem ao melhorar as interações sociais, a autonomia dos estudantes, a colaboração com outros colegas e pessoas mais experientes em qualquer espaço e tempo, dentro ou fora do contexto formal de ensino.

Nesse sentido, a mobilidade permite aos membros de um grupo terem controle físico do seu dispositivo móvel, o que ajuda na coordenação e interação do trabalho colaborativo. Para isto, é necessário que eles possam transportá-lo enquanto estabelecem uma interação face a face ou quando estiverem distantes geograficamente. A comunicação à distância pode ser facilitada com a utilização de aplicativos como videoconferência (Skype, Hangout), ferramentas de bate-papo por meio de textos, áudios, vídeos ou imagens (Gtalk, Facebook, WhatsApp), fóruns de discussões e produção colaborativa (Blogger, Google Drive, Google Maps) e compartilhamento (Youtube, Instagram, Dropbox).

Essas tecnologias podem fornecer suporte para a aprendizagem colaborativa com ênfase em uma ação mediada. Conforme Nascimento e Castro Filho (2014) há três maneiras de se conceber esse suporte: os estudantes e professores trabalham de forma colaborativa com tecnologias de uso móvel e individual; o trabalho pode ser feito de forma simultânea, quando os membros de um grupo estão reunidos para realização de uma tarefa através de um aplicativo colaborativo; a colaboração não é feita via ferramenta e sim através da interação entre os membros do grupo. Essa forma é similar à colaboração com o uso de ferramentas analógicas como lápis e papel, no entanto, dá ênfase nos processos de interação presenciais e virtuais.

Outros autores (RAZAQUE; ELLEITHY, 2012; BALOCH; RAHMAN; HAD, 2012; REYCHAV; WU, 2015) concordam que MC-Learning na educação se dá a partir de uma sinergia entre estudantes e professores para lidar com um problema, estimulando a atividade social, a colaboração e o compartilhamento das informações. Para que esses elementos aconteçam é necessário que a aprendizagem colaborativa móvel forneça recursos e funcionalidades para apoiar a partilha de conhecimento.

Apesar disso, o aspecto pedagógico da MC-Learning não foi explorado nos estudos citados. Em contrapartida, acredita-se em uma aprendizagem colaborativa que, 
auxiliada por dispositivos móveis, possa extrapolar os muros das escolas em diferentes contextos de aprendizagem. Além disso, é necessário conhecer as estratégias pedagógicas utilizadas pelos professores para relacionar o que se ensina e se aprende na escola com o que é vivenciado fora dela, bem como conhecer as possibilidades que esses recursos oferecem à educação.

Após essa discussão, o próximo item apresenta os procedimentos metodológicos.

\section{METODOLOGIA}

Este estudo foi desenvolvido em uma escola pública municipal do interior do Ceará, aqui denominada de "Escola Verde", situada em uma região litorânea. A preferência por essa instituição adveio dos seguintes elementos: disponibilidade de dispositivos móveis para beneficiar o processo de ensino e aprendizagem de professores e estudantes; acesso à Internet; o ingresso da pesquisadora como formadora do curso contemplado nesses dois Projetos; e, assentimento da Escola.

Diante disso, observou-se a prática docente de uma professora do Ensino de Ciências - designada pelo nome fictício de Prof. a Júlia, devido seu interesse em desenvolver um projeto com os seus estudantes durante as aulas de Ciências, usando os dispositivos móveis: tablet e netbook.

Refletindo sobre a questão que norteou essa investigação: Como as tecnologias móveis podem apoiar professores e estudantes na produção colaborativa de conhecimentos? Especifica-se o paradigma interpretativo com abordagem qualitativa, visto que clarifica os fenômenos a partir de seu contexto.

Em relação ao método, foi selecionado a pesquisa-ação que tende a envolver, segundo Barbier (2004), uma ação coletiva de pessoas interessadas em contribuir para a resolução imediata de preocupações práticas, nas quais estão envolvidas, agindo conforme uma estrutura negociada.

Portanto, tais elementos foram avaliados e vivenciados, tanto na perspectiva de integração entre a professora com sua turma de estudantes do $7^{\circ}$ ano do Ensino Fundamental e pesquisadora quanto na colaboração das atividades. Por esse motivo, foi necessário apoiar situações que levassem à solução coletiva dos possiveis conflitos, pois as divergências enriquecem a experiência: abrir novas linhas de pensamento acerca do que está sendo realizado, fortalecer as relações entre pares e promover a maturação. 
Neste sentido, professora e pesquisadora deliberaram estratégias para a realização de um projeto educativo na escola com práticas colaborativas a serem desenvolvidas com uma turma de estudantes. Assim, planejaram atividades que permitiram troca de informações e produção coletiva entre estudantes com o apoio de dispositivos móveis e aplicativos que admitiram o compartilhamento de informações, como também a comunicação síncrona e assíncrona além da escola.

Essa pesquisa não teve a intenção de impor à investigada, em seu trabalho docente, uma estrutura padrão e/ou material completo, pelo contrário, todo o processo foi construído conforme suas expectativas, interesses, com base nos resultados gerados, progressivamente, compreendendo as ações da participante envolvida na investigação, fazendo referências às suas origens e vivências e a partir daí desenvolver o trabalho colaborativo. Pensando nisso, foi selecionado o método de pesquisa-ação que estimula o docente a questionar suas próprias ideias, teorias, práticas e seus contextos como elementos de análise.

A coleta de dados representou um processo dinâmico realizado pela pesquisadora, tendo como instrumentos: entrevistas com a Prof. ${ }^{\circ}$ Júlia; observação; diário de campo; fotografias e áudios. Estes contemplam informações necessárias à investigação para a compreensão da prática docente ao empregar dispositivos móveis no dia a dia da escola.

Pensando nisso, foram elaborados três roteiros de entrevistas semiestruturadas como instrumentos primordiais para a coleta de dados na pesquisa. A primeira foi aplicada no início da pesquisa, a fim de levantar alguns dados pessoais e a trajetória profissional da Prof. ' Júlia, de modo a identificar concepções, dificuldades e necessidades sobre o uso das tecnologias na educação, contemplando os seguintes itens: a formação, a experiência profissional e a relação entre tecnologia e prática docente.

A segunda entrevista para definir as etapas do projeto sobre sustentabilidade e tecnologias móveis, assim a Prof. ${ }^{\circ}$ Júlia foi questionada sobre o que esperava que os estudantes aprendessem com os dispositivos móveis, bem como sua concepção acerca do que vinha a ser uma aprendizagem colaborativa móvel.

A última foi realizada após a finalização do projeto desenvolvido na escola. Essa entrevista teve como finalidade atender três aspectos relacionados às etapas da pesquisa: prática docente, processo de aprendizagem colaborativa móvel e o uso dos dispositivos móveis. Dessa forma, as entrevistas, observações e diário de campo possibilitaram analisar as estratégias usadas pela professora no uso dos dispositivos móveis em sua prática pedagógica. 


\subsection{FASES DO DESENUOLUIMENTO DA INUESTIGAÇÃO}

A partir dos ciclos da pesquisa-ação descritos por Elliot (1993) e Barbier (2004), todas as etapas foram discutidas com a Prof. ${ }^{a}$ Júlia, diretamente envolvida na realização do projeto com os seus estudantes do $7^{\circ}$ ano.

0 modelo cíclico em espiral que, segundo Elliot (1993), apresenta os elementos relacionados ao planejamento, ação, observação, reflexão e avaliação estão vinculados de maneira muito estreita e representam as fases do projeto. Para o autor, os ciclos constituem a base para revisões contínuas do progresso da pesquisa. Portanto, este modelo tem ênfase na inter-relação da ação com a reflexão. De acordo, Barbier (2004, p. 83) salienta que "agindo em espiral com a reflexão, a ação questiona ininterruptamente o discurso estabelecido."

Assim, com base no modelo de investigação-ação de Elliot (1993) foi possível observar todos os três ciclos da pesquisa, principalmente a execução das atividades realizadas com o apoio dos dispositivos móveis, seja nas aulas de Ciências, nas aulas de campo, no contraturno de aula e no Laboratório de Informática Educativa (LIE).

No primeiro ciclo, ainda na primeira entrevista, a pesquisadora estabelece contato com a professora e indaga sobre a sua relação com a tecnologia. A Prof ${ }^{a}$ Júlia declarou que não tinha muita afinidade e achava que a escrita analógica era o único caminho para aprender, pois para ela a tecnologia era algo difícil de lidar, como cita na entrevista: "Eu pensava assim: eu não sei, não vou conseguir, então vou deixar pra lá. Eu não sabia nem abrir um e-mail! Perdi muitos cursos por causa disso." (informação verbal).

No entanto, isso mudou quando ela ganhou um smartphone e percebeu nele a necessidade de aprender a usar os recursos, pois tanto a direção como os estudantes haviam criado um grupo no WhatsApp (aplicativo de mensagens instantâneas). Ela compreendeu que as tecnologias poderiam melhorar sua relação com os estudantes, pois ela se preocupava muito com a evasão que crescia consideravelmente.

Contagiada pela temática "sustentabilidade e tecnologias móveis", discutida nas reuniões de planejamento, a Prof. ' Júlia iniciou a discussão desse tema em suas aulas, sempre direcionando ao plano de curso de Ensino de Ciências para a terceira e quarta etapa do ano letivo que versava sobre as características dos reinos vegetais e animais e a importância da preservação da fauna e flora com ênfase no reflorestamento de áreas devastadas.

No segundo ciclo, a elaboração e reflexão constante do plano de ação do projeto com a professora acontecia nos dias de seu planejamento, procurando distribuir o tempo 
entre sessões de estudo, reflexão, planejamento e acompanhamento das ações a serem realizadas.

A Prof. . Júlia trabalha 40 horas na Escola Verde: 12 horas são destinadas ao planejamento e as outras 28 são dedicadas ao ensino na sala de aula. Uma observação pertinente a essa discussão foi levantada na entrevista com a professora que deixou claro sua indignação com tal regime, já que possui muitas turmas de estudantes e que doze horas não são suficientes para se aprimorar e muito menos se dedicar ao ato de planejar.

Por mais que a Prof. ${ }^{\circ}$ Júlia soubesse o objetivo que pretendia alcançar com este trabalho, ela não queria determinar todas as fases do projeto com a pesquisadora de uma única vez. Em razão disso, sempre que possível, procurava convidar alguns estudantes para participarem dos encontros de planejamento. Assim, ficou determinado que os planos de ação seriam gradativamente planejados, uma vez que a intenção era aproximar os discentes de modo que eles se sentissem pertencentes, parceiros em todas as etapas do processo.

Em um desses encontros surgiu a questão-problema do projeto sobre sustentabilidade: como as tecnologias móveis podem nos ajudar a melhorar o bosque da nossa cidade? Dessas discussões o projeto nasceu e foi chamado de "Reflorestamento e Tecnologia Móvel: cuidando da arborização do bosque". A justificativa, seus objetivos e suas atividades foram desenvolvidos com base no cuidado e preservação do meio ambiente, nas ações sustentáveis, na utilização de dispositivos móveis para favorecer o ensino, a aprendizagem e a produção coletiva dos estudantes e no protagonismo juvenil que colabora para a formação de pessoas mais autônomas e comprometidas socialmente.

Depois desse primeiro momento, percebeu nos demais encontros de planejamento, a necessidade que a Prof. ' Júlia tinha de inovar usando os aplicativos e dispositivos móveis na sua prática docente, de desenvolver um projeto social e de delegar ações aos estudantes. A partir das negociações de ideias da turma, durante as suas aulas de Ciências, a Prof." Júlia identificava as habilidades de cada equipe e anotava em seu caderno. Em seguida, nos encontros, apresentava para a pesquisadora e juntas planejavam atividades, selecionavam e estudavam os aplicativos on-line e off-line que promovem produções colaborativas a serem realizadas em um determinado período de tempo.

No terceiro ciclo, a professora continuou acompanhando e refletindo as ações com a pesquisadora semanalmente. As atividades eram desenvolvidas e avaliadas com vistas à integração das tecnologias móveis ao currículo e à realização de novas ações.

Esse processo beneficiou a correção de rumos, uma vez que a sequência das atividades era refletida, discutida, avaliada e avançada, como é de esperar a toda ação pedagógica. Assim, o currículo se torna vivo, se reconstrói e ressignifica, e não se restringe à transferência e aplicação do conteúdo determinado, todavia se desenvolve em dois momentos, 
conforme os autores: reconstrução, em que a professora prepara o planejamento de sua disciplina segundo as características do contexto e modo de realizar o trabalho pedagógico; ressignificação, quando a professora transforma o planejamento da prática pedagógica, a partir das necessidades de seus estudantes, do seu fazer e de sua reflexão sobre a ação (JARDILINO, SAMPAIO, 2019).

Desde o início, a proposta foi avaliar, a partir da visão docente, práticas colaborativas apoiadas pelos dispositivos móveis desenvolvidas em uma turma de estudantes. Com o surgimento do projeto, tal proposta foi ressignificada, uma vez que se tinha também a preocupação de cuidar do bosque ao lado da escola, laboratório vivo que proporciona diferentes experiências não só pedagógicas, mas de vida para os estudantes e comunidade. Além disso, a professora tinha consciência de que os estudantes sabiam e possuíam mais facilidade no manejo dos dispositivos móveis do que ela, assim, procurou organizar seus horários para que estivesse sempre em contato com eles, seja dentro ou fora da sala de aula.

Foram realizados 20 encontros com a Prof. ${ }^{a}$ Júlia para execução do projeto com a turma de estudantes (40 horas-aula), assim distribuídos: 10 aulas de Ciências (20 horas-aula), sendo 4 na sala de aula e 3 no LIE (14 horas-aula) para a criação do mapa colaborativo, palestra proferida por um convidado, pesquisa na internet, registro de fotos, criação colaborativa de planilha eletrônica, análise dos dados coletados e elaboração de um gráfico; 3 aulas de campo (6 horas-aula) para explicar e confrontar os conteúdos teóricos e práticos; 10 encontros no contraturno (20 horas-aula) para atividades de filmagem de vídeo, de entrevista com uma representante que reside há mais tempo na comunidade, próximo à escola, da geração de dados do monitoramento on-line das plantas, da criação da logomarca do projeto e desenho do bosque.

Foram despendidas 8 horas-aulas para desenvolver o mapa colaborativo do bosque com representações reais de imagens, textos, vídeos e links. Já para o aplicativo de planilha foram necessárias 10 horas-aulas distribuídas para execução de 3 atividades diferentes: análise das respostas do formulário de monitoramento das plantas; identificação e quantidade de espécies de plantas; criação de gráfico. As outras 4 horas-aulas foram destinadas para uma palestra na própria escola, plantio de mudas no bosque e registros de fotos.

As atividades no contraturno duravam aproximadamente 2 horas e foram essenciais para dar continuidade às produções, conforme citado anteriormente pela Prof. ${ }^{a}$ Júlia, duas horas não são suficientes para conhecer, debater, refletir, testar, produzir.

Outros aplicativos também apareceram: WhatsApp para comunicação síncrona e compartilhamento de informações; Youtube para armazenar os vídeos produzidos pelos estudantes; Facebook para divulgação do projeto. 0 software Movie Maker também foi usado 
para a montagem de vídeos. Todos estes recursos viabilizaram a produção discente e facilitaram a comunicação entre professora, estudantes e comunidade.

Em alguns momentos, os estudantes do $7^{\circ}$ ano $D$ realizavam atividades em casa que ficavam registradas nos aplicativos on-line usados, tais como: Planilha e Formulário do Google Drive e WhatsApp. Em outras ocasiões, o registro das ações do projeto era feito pela Prof. ${ }^{a}$ Júlia com a ajuda operacional da pesquisadora no blog e/ou na Fanpage da escola pelas diretoras.

Essa distribuição funcionou bem durante todo o período de planejamento e execução do projeto, outros horários foram usados para conversas informais entre a professora e a pesquisadora, especialmente no último mês do projeto para organizar e preparar melhor a culminância.

\section{RESULTADO E DISCUSSÃO}

Ensinar está muito além da explicação de um conteúdo. Veiga (2005, p. 24) explica que o ensino não se restringe à transferência de conhecimentos, "uma vez que os processos mentais, seja da parte do professor ou do aluno, se põem como centrais na configuração do ensino". Isso revela que se trata de uma ação docente da qual deriva a aprendizagem do aluno, buscando uma construção coletiva do conhecimento.

Dessa forma, logo na primeira aula, a Prof. ${ }^{a}$ Júlia expôs o tema sustentabilidade à turma com um vídeo que explora a importância do desenvolvimento sustentável, preservação do ambiente e avalia a pressão do consumo das populações humanas sobre os recursos naturais. Enquanto isso, os estudantes iam respondendo e dando exemplos de poluição no bairro onde moram, na praça da cidade, nas ruas, inclusive no bosque ao lado da escola, apontando vários problemas: muito lixo, o mato estava crescendo, o córrego estava poluído. Desta forma, a Prof ${ }^{a}$ Júlia pediu que a turma se organizasse em equipes para pensar estratégias de como preservar o bosque a partir das ações pensadas no projeto.

Diante disso, nos encontros de planejamento, professora e pesquisadora começaram a estudar os aplicativos que seriam utilizados. Segundo a Prof." Júlia, "sem planejamento não se consegue trabalhar a tecnologia, mas também ele não pode ser fechado, ele precisa ser flexível." (informação verbal).

Um dos primeiros aplicativos selecionados foi o Google Maps, pois as atividades necessitavam do mapeamento das plantas da região ao entorno da escola. A partir da necessidade de compartilhar informações e produzir colaborativamente, elegeram alguns 
aplicativos do Google Drive: Planilhas para levantamento, comparação e criação de gráfico sobre os tipos de plantas do bosque e Formulários para o monitoramento on-line.

Todos esses recursos são gratuitos, mas precisam ter uma conta de e-mail, assim, a professora criou uma conta no Gmail e compartilhou os links dos aplicativos com os estudantes em seu blog. Contudo, nos encontros de planejamento, percebeu-se que a professora estava preocupada em ensinar as funcionalidades dos aplicativos aos estudantes. Apesar do seu esforço em aprender, ela não conseguia assimilar todos os passos para produzir mapa, planilha, gráfico e formulário, e isso estava causando nervosismo e ansiedade. Porém, ela reconheceu que tais recursos têm rico valor pedagógico, mas concluiu que não conseguiria sozinha ensinar todas as funções à turma. Assim, pediu à pesquisadora e aos estudantes da própria turma para ajudá-la.

De fato, a professora sabia de suas limitações no uso da tecnologia, então decidiu que em cada atividade tivesse pelo menos um grupo responsável e que esse fosse liderado por um aluno. A estratégia usada pela Prof. ${ }^{a}$ Júlia foi de delegar diferentes ações aos grupos para que pudessem ajudá-la tanto no ensino dos aplicativos quanto no acompanhamento, como ela explica: "Cada grupo tinha um líder e esse me ajudava a verificar se os demais estudantes daquele grupo estão fazendo as atividades, estão envolvidos, caso não, eu chamava para conversar, tudo era anotado, porque depois eu via quem participava." (informação verbal).

Em alguns momentos, apareciam desavenças, desentendimentos entre os estudantes, mas a Prof. ${ }^{a}$ Júlia estava sempre disposta a conversar e mostrar que a participação de todos era importante. Nas entrevistas ela dizia:

\footnotetext{
[...] não tem nem o papel do professor e nem do aluno, ou seja, não está separado, o que se têm são grandes aprendizados, tanto para um quanto para o outro. Eu aprendi muito com eles e eles comigo. É como se eu voltasse a ser criança e aprendesse o b-a, ba da vida, o b-a, ba da tecnologia. Eu ainda estou aprendendo, tenho 23 anos de carreira, mas me vejo ainda na cartilha da tecnologia aprendendo com ela [tecnologia]. (informação verbal).

Acho que nós professores não precisamos saber de tudo, precisamos dar oportunidade ao nosso aluno [...]. Quando eu pedi que você lpesquisadora] mostrasse, ai eles se interessaram e você [pesquisadora] viu que eles só precisaram de uma única aula, né! (informação verbal).
} 


\subsection{CONTEÚDOS CURRICULARES}

A ideia inicial do projeto estava totalmente condizente com os temas abordados nos módulos do plano de curso de Ciências do $7^{\circ}$ ano. Como o projeto foi iniciado no segundo semestre, a Prof. ${ }^{a}$ Júlia explorou os reinos vegetais e animais. Por isso, as características e classificações dos reinos vegetais e animais eram relacionadas e comparadas às espécies que eles conheciam ou que viam no bosque, trabalhadas também em 3 aulas de campo.

A título de exemplo, em uma aula no bosque, a Prof. ${ }^{a}$ Júlia recapitulou o conteúdo sobre os órgãos vegetativos, fazendo as seguintes perguntas: "Quais os órgãos que a gente estudou? Todas as plantas possuem todos esses órgãos? Por exemplo: esta palmeira aqui, ela tem todos os órgãos? Quais os órgãos que ela possui? Quais os órgãos que esse cajueiro possuie" (Diário de campo).

Em seguida, explorou o módulo sobre briófitas e pteridófitas e pediu que os estudantes identificassem no bosque. Somente 10 tablets encontravam-se disponíveis, pois os netbooks estavam sendo utilizados por outra turma. Assim, alguns estudantes ficaram incomodados e perguntaram à Prof. ${ }^{a}$ Júlia se podiam usar seus celulares. A professora consentiu, mas pediu que compartilhassem as fotos com os demais. Em vários momentos, os estudantes preferiram utilizar seu próprio dispositivo, ao invés do que foi fornecido pela escola.

Notou-se um natural apego ao celular, o qual os estudantes estão ambientados. Isto leva a acreditar que as preferências sociais e pessoais parecem afetar a utilização de dispositivos móveis em qualquer lugar, igualmente na escola. Boa parte dos estudantes que tinham celular/smartphone também possuía plano de dados, isso facilitou o envio de mensagens, compartilhamento das fotos e realização das demais tarefas on-line. Apesar do Estado do Ceará ${ }^{3}$ proibir uso de celulares nas escolas, a professora reconheceu a necessidade de estabelecer um objetivo pedagógico muito claro para seu uso (CEARÁ, 2008), pois este instrumento foi contagiado pelos estudantes, disse ela: "Eu quero que os estudantes entendam que podemos usar o celular na escola, desde que tenha um sentido educativo por trás disso." (informação verbal).

Dessa forma, o uso do celular na sala de aula estava proibido na Escola Verde, mas a direção autorizou a sua utilização após solicitação da Prof. ${ }^{a}$ Júlia, visto que apresentou estratégias pedagógicas para a sua inclusão em sua prática docente.

A Lei n. 14.146, de 25 de junho de 2008, dispõe sobre a proibição do uso de equipamentos de comunicação, eletrônicos e outros aparelhos similares, nos estabelecimentos de ensino do Estado do Ceará, durante o horário das aulas. 
Mesmo com diferentes tipos de dispositivos, a professora se concentrou no processo de ensino e deixou os desafios técnicos para os estudantes. Um estudante informou que seu celular tinha uma boa resolução, a partir disso, a Prof. a Júlia teve a ideia de o próprio aluno fotografar situações que precisavam de um alcance maior, por exemplo, o registro dos frutos que ficam na copa das árvores (Diário de campo).

Os estudantes eram, a todo o momento, incentivados pela Prof. a Júlia a fazer perguntas, ficavam apontando as plantas e classificando oralmente, depois, por meio de fotos e textos, registravam os tipos de vegetais existentes no bosque para posteriormente colocálos no mapa colaborativo. A professora inicialmente explicou à turma que a aula seguiria com a explicação sobre reinos vegetais, identificando e classificando as espécies existentes do bosque. Para isso, ela pediu que os estudantes se agrupassem e fotografassem as espécies, em seguida, reforçou a necessidade de tomar nota das plantas, classificando-as em angiospermas e gimnospermas (Diário de campo).

A teoria e a prática possuem relação indissociável que, segundo Zabala (1998), quando revestida de reflexão - ação - transformação, constitui a práxis. Nesse ponto de vista, o professor organiza e pensa o processo educativo. A ação pedagógica conduz o educador a constantes questionamentos sobre o que e como ensinar, o pensar e o agir, para quem e para que ensinar os conteúdos.

Todos participaram, mas um grupo ficou responsável de coletar os registros dos colegas em uma planilha compartilhada do Google Drive. Assim, os estudantes fotografaram, classificaram e colocaram a quantidade de cada espécie existente no bosque.

A segunda aula de campo foi atípica, ela aconteceu em um horário que não pertencia à Prof. ${ }^{a}$ Júlia, que usou outro tempo de aula, perfazendo uma manhã inteira com a turma. Neste dia os estudantes fizeram o plantio de 9 mudas. Estiveram presentes um professor de Artes e outro de Matemática da própria Escola Verde, como também dos estudantes das outras turmas do $7^{\circ}$ ano.

Na ocasião, a Prof. ' Júlia apresentou a versão inicial do mapa colaborativo aos demais participantes. Ela justificou que as atividades não estavam finalizadas, mas que os estudantes apresentariam os resultados na culminância do projeto. Nessa apresentação, ela contou com a ajuda de um aluno que se posicionou em frente ao netbook para acessar o mapa e projetá-lo no telão.

Conforme Liu, Lin, Paas (2014), aprender com atividades baseadas na web possibilita diferentes cenários reais e recursos digitais que podem complementar, integrar e organizar os dados gerados pelas pesquisas dos próprios estudantes. Os dispositivos móveis não estão restritos aos ambientes internos da escola, a informação virtual pode ser integrada ao ambiente real. Os autores ressaltam ainda que os estudantes têm mais oportunidades de se 
envolverem nas atividades escolares quando estas são ao ar livre, comparando o que se vê na sala de aula com situações reais do dia a dia.

Do mesmo modo que a primeira aula de campo, a segunda foi realizada com o apoio de tablets e smartphones. Os estudantes procuraram e fotografaram espécies de animais e classificaram em vertebrados e invertebrados. Encontraram lagartas, girinos, várias espécies de formigas, borboletas, aranhas, marimbondos e um assustado "soinho" (Macaco Saguil) na parte superior de uma das mangueiras. A professora perguntava sobre as espécies encontradas: "Gente, qual desses animais é da família dos anfibios? Quantos são invertebrados? 0 s vertebrados estão classificados de que forma? 0 s estudantes respondiam à medida que fotografavam" (Diário de Campo). Em seguida, deixou claro que além das aulas, os temas deveriam ser estudados e melhor aprofundados nas leituras. Assim, levou os estudantes para o LIE e iniciou uma pesquisa na Internet sobre os animais, como também deu continuidade ao mapa colaborativo.

Segundo a Prof. a Júlia, os dispositivos móveis ajudaram a trabalhar o conteúdo de várias formas diferentes, disse ela: "A gente criou um mapa colaborativo, fez pesquisa na Internet, tirou fotos com o tablet e celular, criou tabelas e gráfico no netbook, desenhou, criou vídeos, tudo isso com o objetivo de aprender os conteúdos." A professora ressaltou ainda que os estudantes não acreditavam que aprenderiam os assuntos do livro de forma diferente, e continuou: "Quem levou essa tecnologia para os estudantes fomos nós, eu e você [pesquisadora]! Muitos deles já sabiam usar, mas nunca pensaram que poderiam aprender os conteúdos que a gente vê na sala dessa forma. Isso não é coisa da minha cabeça não! Tá lá no blog" (informação verbal). Seguem abaixo alguns comentários dos estudantes que a Prof. ${ }^{a}$ Júlia se refere:

0 projeto está sendo uma experiência muito bacana, está dando para aprender muitas coisas até conheci uma fruta nova, espero que esse projeto continue por muito tempo. (informação verbal).

Apendi muitas coisas. A gente usou os tablets e até o celular. Foi legal usar tudo isso a aula foi muito divertida e a gente fez um trabalho sobre as gimnospermas (informação verbal).

De acordo com Sharples, Taylor e Vavoula (2010) a tecnologia móvel, em contextos diferentes de aprendizagem, pode permitir aos estudantes a aprender e a explorar seu mundo em contínua comunicação com e através dessa tecnologia. Ressaltam ainda que a educação na era móvel não substitui a educação formal, nem a rede mundial substitui o livro didático; em vez disso, oferece uma maneira de estender o apoio de aprendizagem fora da sala de aula nas conversas e interações da vida cotidiana. 


\subsection{DISPOSITIUOS MÓUEIS E CONECTIUIDADE}

A vantagem de estar a qualquer hora e em qualquer lugar usando um dispositivo móvel favoreceu a realização das atividades. Enquanto a Prof. ${ }^{a}$ Júlia explicava a necessidade de registrar por meio de fotos as plantas do bosque, de classificar e de pesquisar seus nomes científicos, os alunos compartilhavam fotografias e informações através de Bluetooth ou anexavam no grupo pelo WhatsApp.

Esse compartilhamento de informações foi tão naturalmente interiorizado pela Prof. a Júlia que ela nem se deu conta que estava usando de maneira diferente daquilo que fazia antes desta experiência, por exemplo: imprimir ou digitalizar as imagens, fotocopiá-las e distribuil-las aos alunos (Diário de campo).

Nas aulas de campo, a Prof. ${ }^{a}$ Júlia recomendava à turma que fotografasse as espécies de vegetais e animais, pois em outro momento usaria tais registros para compor o mapa colaborativo. Nas aulas seguintes, os alunos apresentavam suas fotos acompanhadas de informações que haviam pesquisado na Internet. Isso também aconteceu ao comparar os tipos e quantidade de plantas existentes no bosque. Na maioria das vezes, os dados foram armazenados nos tablets e/ou netbooks e depois compartilhados aos demais. Em outras ocasiões os registros estavam nos smartphones dos alunos e anexados no grupo do WhatsApp.

A Prof. ${ }^{a}$ Júlia percebeu que alguns alunos possuíam planos de dados em seus smartphones e optavam por responder o monitoramento on-line do bosque em seu próprio dispositivo ao invés do tablet. Alguns roteavam/partilhavam sua Internet com os colegas, oportunizando acesso e participação nas atividades on-line.

De acordo, Santaella (2013, p. 15) reforça que essa facilidade faz com que o aluno troque experiências de aprendizado de forma inédita. A autora revela que "redes sem fio e, consequentemente, móveis são a tônica tecnológica do momento. Isso disponibiliza um tipo de comunicação ubíqua, pervasiva e, ao mesmo tempo, corporificada e multiplamente situada [...] nos deslocamentos espaço-temporais dos indivíduos." lsso também foi percebido durante o levantamento dos tipos de plantas, animais, na criação de vídeos e monitoramento on-line.

Diante dessa discussão, entende-se que a mobilidade pode acontecer sem acesso à Internet e sem trocas de informações. Já a ubiquidade está ligada à computação móvel em que a conexão é sustentada por um dispositivo, independente do movimento do indivíduo, por exemplo, os smartphones usados por alguns alunos para monitorar as plantas do bosque, a partir de um formulário eletrônico ou planilha do Google Drive, cujo link estava 
disponível no blog da Prof. ' Júlia que poderia ser acessado em qualquer tempo e espaço, como também a possibilidade de aprofundar a pesquisa sobre as plantas, armazenar e compartilhar informações.

Para a Prof. ${ }^{a}$ Júlia esta tecnologia facilitou a organização, o compartilhamento da informação e aproximou os conteúdos curriculares à realidade dos alunos seja na sala de aula, no campo, em casa ou em outro lugar, ela justifica:

A gente é móvel, os alunos principalmente [Risos]. Eles são inquietos não conseguem ficar muito tempo em um só lugar. Com a tecnologia móvel, os alunos puderam se locomover para ajudar os colegas, levar de um canto para outro, isso facilita a interação. Senti que eles se agruparam melhor, produziram várias coisas de forma colaborativa e depois compartilhavam a todo instante. (informação verball).

A Prof. a Júlia deixava os alunos à vontade para fotografar, enviar vídeos, músicas ou responder os itens do formulário feito no Google Drive. Como os aplicativos compartilhados poderiam ser acessados em qualquer tempo e lugar, os alunos também usaram os horários no contraturno de aula para participar respondendo ou registrando algo. Ela também percebeu que o fato de os alunos levarem seus smartphones para registrar suas observações a qualquer hora foi um fator motivador e que eles mesmos demandavam critérios de exigências em relação ao produto final.

Como por exemplo, a atividade de monitoramento on-line foi bem assimilada pelos alunos, principalmente quando se depararam com os garis e escavadeiras manipuladas pelos demais funcionários da Secretaria de Infraestrura da cidade fazendo a limpeza do bosque.

Após quatro semanas acompanhando as atividades realizadas no bosque, a Prof. a Júlia mostrou na sala de aula, com ajuda da pesquisadora, as respostas do formulário feito no Google Drive sobre o monitoramento on-line. Afinal, eles precisavam analisar os dados gerados com o objetivo de identificar problemas relacionados ao crescimento saudável das plantas e pensar estratégias para solucioná-los. Os alunos ficaram impressionados com a quantidade de itens respondidos.

Observou-se que todos os registros foram feitos em dias e horários diferentes, principalmente nos horários que não eram de aula. A elaboração do formulário não se resumiu ao levantamento da situação das plantas no bosque, e sim oportunizou debates e soluções para os problemas naturais e sociais do ambiente. Estes debates foram encorajados pela professora que apresentava questões sobre os dados gerados e apresentados na planilha.

Essa atividade permitiu compartihar e discutir nas aulas os dados encontrados no campo, como também em contextos não formais onde os alunos não estavam na escola e 
muito menos em seus horários de aula. Segundo Vieira et al. (2005), os espaços não-formais oferecem a aprendizagem fora de um ambiente clássico e de um currículo formal, ela pode acontecer a todo o momento e é influenciada pelo ambiente e por situações particulares vividos pelo indivíduo.

Segundo Sharples, Taylor e Vavoula (2010), usar dispositivos móveis para explorar o campo de investigação, receber e compartilhar informações com os colegas e depois voltar à escola para discutir e desenvolver suas interpretações com a turma tem mais sentido pedagógico pelo fato dessas tecnologias permitirem a relação entre as experiências do mundo com os assuntos estudados de forma dinâmica. Ao mesmo tempo, os autores recorrem a Paulo Freire, que relaciona a contextualização com a problematização da realidade vivida, quando se referem à capacidade de extrair, de avaliar, de discutir o contexto da realidade.

\subsection{PRODUÇÃO COLABORATIUA}

No mapa colaborativo a Prof. ${ }^{a}$ Júlia deixou claro a necessidade de identificar as espécies de plantas e animais do bosque, pedindo que os estudantes organizassem informações, dando origem a um ciclo de ações dinâmicas (compartilhar; criar marcador; inserir fotografia; pesquisar; ler; refletir; tomar decisões; digitar). Isso foi estabelecido a partir dos assuntos explorados nas aulas, ou seja, tratando os conteúdos curriculares dentro da escola ou explorando-os através dos dispositivos móveis fora dela: nos espaços públicos ou entrevistando pessoas da comunidade.

Os registros foram cuidadosamente pontuados no mapa colaborativo, no qual os estudantes inseriram fotos e textos com a descrição de cada planta, editaram as filmagens e postaram no mapa, marcando as áreas com linhas e formas geométricas.

A última versão do mapa colaborativo foi exibida pelos próprios estudantes na sala de aula com o objetivo de reconhecer o papel de cada um no processo. Na ocasião, a Prof. ${ }^{a}$ Júlia parabenizou a turma e reforçou que a colaboração de todos foi importante no processo. 
Figura 1 - Terceira e última versão do mapa trabalhado pelos alunos

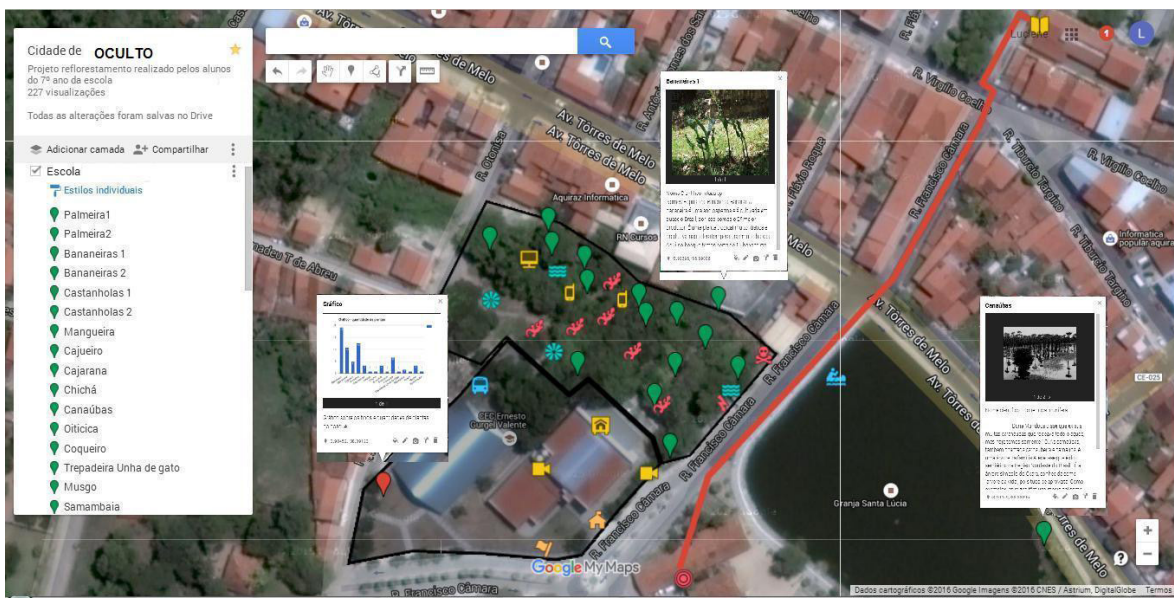

Fonte: Nascimento (2016, p. 192).

A utilização do Google Maps na prática escolar precisa ser mediada pelo docente a fim de promover momentos de reflexão durante a ação colaborativa, já que sua plataforma proporciona trabalho coletivo. Quando o aluno A criava um marcador e inseria um texto usando um determinado netbook, o aluno $\mathrm{B}$, em outra máquina, ajudava-o a inserir outros elementos, para isso os estudantes refletiam, discutiam a melhor forma de inserir as informações e tomavam decisões de fazê-las em conjunto (Diário de campo).

Constatou-se que esse aplicativo é também um espaço de aprendizagem que utiliza ferramentas on-line como instrumentos de reflexão do conhecimento. No entanto, Laru, Näykki e Järvelä (2015) consideram que o planejamento docente, juntamente com o apoio dos dispositivos móveis, são elementos condicionantes para que haja aprendizagem. Dessa forma, a Prof. ' Júlia incorporou atividades que incentivaram momentos de partilha e discussão entre os estudantes.

As diferentes atividades produzidas pelos grupos foram ressaltadas, porque a professora deixava-os à vontade para criar, desde que dessem seguimento aos temas estudados e não ultrapassem os prazos dados para finalização das tarefas. 0s estudantes contribuíram com o que sabiam fazer, ou seja, o produto final apresentou muitas características pessoais dos alunos, isso foi visto, principalmente, nos vídeos e desenhos. 


\section{CONSIDERAÇÕES FINAIS}

As conquistas, os desafios e as dificuldades de combinar vários dispositivos móveis (pedagógicos, técnicos e funcionais) com propostas de atividades que extrapolaram as paredes da sala de aula, agregando diferentes mídias, possibilitam que estudantes produzam de forma colaborativa com alto potencial para comparar, vivenciar e transformar os conteúdos estudados na sala de aula em situações reais, próximas do dia a dia.

Apesar de boa parte das atividades com os tablets e netbooks ter, necessariamente, partido das intenções e orientações da Prof. a Júlia, para os estudantes foi como se todas as tarefas tivessem sido descobertas por eles. Esse sentimento talvez tenha nascido e externado pela professora, pois a todo o momento deixava claro que eles sabiam usar as tecnologias mais do que ela.

Ademais, as ações mediadas pelas tecnologias móveis tiveram, ainda, o potencial de transformar a disciplina de Ciências da Prof ${ }^{\circ}$ Júlia em aulas mais próximas à realidade vivida na comunidade. Ao identificar os pontos positivos dessa experiência, a Prof. ${ }^{a}$ Júlia apontou quatro situações que atestam, conforme a literatura, algumas características da aprendizagem móvel colaborativa neste estudo, são elas: a capacidade de fazer as atividades em conjunto, pois os estudantes se ajudavam para desenvolver uma determinada ação. Por exemplo, o mapa colaborativo onde as informações (imagens, textos, links e vídeos) eram inseridas a partir dos marcadores criados pelos estudantes. Tudo foi negociado, eles não apagavam o que o outro fazia, porque sabiam que o mapa era de todos; a comunicação virtual era frequente, seja dentro ou fora da escola; o reconhecimento das habilidades de cada um foi apontado pelos próprios estudantes que se organizavam em grupos, não só por afinidade, mas também por aptidões: os que gostavam de desenhar, os de escrever, os de fazer slides, os de fotografar, os de filmar e montar vídeos; a possibilidade de usar várias mídias: imagens, vídeos, textos e músicas em um aplicativo; a integração dos aplicativos e dispositivos móveis.

0 foco da MC-Learning não é o docente, o estudante e nem a sua tecnologia, mas a interação comunicativa realizada entre esses três elementos. Em um primeiro nível de análise, a MC-Learning tenta compreender as pessoas e os dispositivos móveis em fluxo contínuo através de ambientes dinâmicos que podem ser locais ou virtuais. Em segundo plano, ela avalia o ensino e a aprendizagem como um processo de conversação dentro de contextos diferentes que permitem compartilhamento, negociação de ideias e produção colaborativa (SOUSA; MARQUES, 2019; THERRIEN; AZEVEDO; LACERDA, 2017).

Associar as tecnologias móveis em práticas colaborativas no contexto educativo implica pensar nos benefícios e dificuldades decorrentes de uma variedade de recursos 
disponíveis no mercado e na possibilidade de apoiar novas estratégias pedagógicas. Essa integração ficou bastante representado no projeto, pois a professora atribuiu maior responsabilidade aos estudantes na construção da sua aprendizagem: investindo no protagonismo juvenil; ensinando-os a lidar com as transformações do meio ambiente, com as frustrações, com a criticidade dos fatos.

Observou-se no estudo que o mais importante não foi o netbook, tablet e nem o smartphone, mas a forma como a professora conduziu, mediou todo o processo de utilização desses dispositivos com seus alunos. Se os estudantes têm à mão uma tecnologia que proporciona gravar vídeo, fotografar situações distintas, localizar, mapear, registrar e acessar Internet não faz muito sentido pedir-lhes que apenas usem o caderno e o lápis. A professora admitiu que seu desconhecimento inicial sobre as potencialidades das tecnologias móveis retardou sua decisão de integrá-las no seu trabalho docente. Porém, reconheceu que precisava sair da zona de conforto, caso contrário não teria atenção e compromisso dos estudantes.

Seguramente, há muita coisa a fazer nesta área. Por isso, este estudo permite ensejar propostas que poderão constituir trabalhos futuros, representando continuidade natural dos resultados obtidos. Assim, parece fazer sentido modificar o projeto de lei que proíbe o uso de celulares nas escolas. Outra solução que poderia ser implantada rapidamente, com a permissão da gestão escolar, é incentivar os estudantes a levarem seus próprios dispositivos móveis para serem usados dentro dos espaços educativos, principalmente, nas atividades mediadas pelos docentes. Isto acarretaria um barateamento dos custos com a manutenção. Contudo, é importante pensar no planejamento dos objetivos pedagógicos de sua utilização e no investimento de conexão sem fio de qualidade.

\section{REFERÊNCIAS}

ALMEIDA, M. E. B. de; VALENTE, J. A. Tecnologias e currículo: trajetórias convergentes ou divergentes. São Paulo: Paulus, 2011, p. 6-8.

ARAÚJO, R. M.; ESTEVES, M. M. A formação docente, inicial e contínua, para o trabalho com adultos em Portugal: o olhar dos professores. Educação \& Formação, Fortaleza, v. 2, n. 4, p. 18-35, 2017. Disponivel em: https://revistas.uece.br/index.php/redufor/article/view/१२1. Acesso em: 23 maio 2019.

BALOCH, H. Z; RAHMAN, A. A.; HAD, N. Mobile Collaborative Informal Learning Design: Study of Collaborative Effectiveness Using Activity Theory. International Journal of Interactive Mobile Technologies, Nova York, v. 6, n. 3, 2012.

BARBIER, R. A pesquisa-ação. Brasilia: Liber Livro Editora, 2004. 
BERRIBILI, E.; MLLL, D. Impacto cognitivo do uso intensivo da internet: a autonomia dos estudos com dispositivos na adolescência. Educação \& Formação, Fortaleza, v. 3, n. 9, p. 177-188, 2018. Disponível em: https://revistas.uece.br/index.php/redufor/article/view/862/765. Acesso em: 23 maio 2019.

CEARÁ. Lei n.14.146, de 25 de junho de 2008. Dispõe sobre a proibição do uso de equipamentos de comunicação, eletrônicos e outros aparelhos similares, nos estabelecimentos de ensino do Estado do Ceará, durante o horário das aulas. Diário Oficial, Ceará, CE, 30 set. 2008. Disponível em: http://www. al.ce.gov.br/legislativo/legislacao5/leis2008/14146.htm Acesso em: 12 set. 2019.

ELLIOT, J. El cambio educativo desde la investigación-acción. Madrid: Morata, 1993.

FANTIN, M. Educação, aprendizagem e tecnologia na pesquisa-ação. Educação \& Formação, Fortaleza, v. 2, n. 6, p. 87-100, 2017. Disponível em: https://revistas.uece.br/index.php/redufor/article/ view/161/143. Acesso em: 23 maio 2019.

FERNANDES, A. P. 0 ser e o saber-fazer docente nas escolas das ithas de Belém/PA. Educação \& Formação, Fortaleza, v. 1, n. 3, p. 32-49, 2016. Disponível em: https://revistas.uece.br/index.php/redufor/article/view/112/95. Acesso em: 23 maio 2019.

FERREIRA, E. M.; MUNIZ, D. M.; OLIVEIRA JÚNIOR, 0. Sequências didáticas, tecnologias e aprendizagem de língua portuguesa na escola de ensino médio. Educação \& Formação, Fortaleza, v. 3, n. 9, p. 71-87, 2018. Disponível em: https://revistas.uece.br/index.php/redufor/article/view/857/759. Acesso em: 23 maio 2019.

FONSECA, G. As tecnologias de informação e comunicação na formação inicial de professores do $1^{\circ}$ ciclo do ensino básico - fatores constrangedores invocados pelos formadores para o uso das tecnologias. Educação \& Formação, Fortaleza, v. 4, n. 11, p. 3-23, 2019. Disponivel em: https://revistas. uece.br/index.php/redufor/article/view/254/1149. Acesso em: 23 maio 2019.

HSU, Y.; CHNG, Y. Mobile computer supported collaborative learning: A review of experimental research. British Journal of Educational Technology, Londres, v. 44, n. 5, p. E111-E114, 2013.

JARDILINO, J. R.; SAMPAIO, A. M. Desenvolvimento profissional docente: reflexões sobre política pública de formação de professores. Educação \& Formação, Fortaleza, v. 4, n. 10, p. 180-194, 2019. Disponivel em: https://revistas.uece.br/index.php/redufor/article/view/848/1089. Acesso em: 23 maio 2019.

LARU, J.; NÄYKKI, P.; JÄRVELÄ, S. Four stages of research on the educational use of ubiquitous computing. IEEE Transactions on Learning Technologies, Nova York, v. 8, n. 1, p. 69-82, 2015.

LIU, T.; LIN, Y.; PAAS, F. Effects of prior knowledge on learning from different compositions of representations in a mobile learning environment. Computers \& Education, Washington, v. 72, p. 328-338, 2014.

MEHDIPOUR, Y.; ZEREHKAFI, H. Mobile Learning for Education: Benefits and Challenges. In International Journal of Computational Engineering Research, Nova Delhi, v. 3, n. 6, p. 93-101, 2013. 
NASCIMENTO, K. A. S. do, CASTRO FLLHO, J. A. de. Aprendizagem Colaborativa com Suporte de Dispositivos Móveis no Projeto UCA In: TISE - XIX Conferência Internacional sobre Informática na Educação, 2014, Fortaleza. Anais Nuevas Ideas en Informática Educativa. Chile: Universidad de Chile, Facultad de Ciencias Fisicas y Matemáticas, 2014. v. 10. p. 940-946.

NASCIMENTO, K. A. S. MC-Learning: Práticas Colaborativas na Escola com o Suporte da Tecnologia Móvel. 2016. Tese (Doutorado em Educação Brasileira) - Universidade Federal do Ceará, Fortaleza, 2016. Disponivel em: http://www.repositorio.ufc.br/handle/riufc/21227. Acesso em: 23 maio 2019.

PEREIRA, A.; RIBEIRO, C. S. A culpabilidade pelo fracasso escolar e a interface com os "problemas de aprendizagem" em discurso. Educação \& Formação, Fortaleza, v. 2, n. 5, p. 95-110, 2017. Disponível em: https://revistas.uece.br/index.php/redufor/article/view/138. Acesso em: 23 maio 2019.

RAZAQUE, A.; ELLEITHY, K. Interactive Prototypes for Mobile Collaborative Learning (MCL) to Substantiate Pedagogical. International Journal of Interactive Mobile Technologies, Nova York, v. 6, n. 1, 2012.

REYCHAV, I. WU, D. Mobile collaborative learning: the role of individual learning in groups through text and video content delivery in tablets. Computers in Human Behavior, Washington, v. 50, p. 520-534, 2015.

SANTAELLA, L. Comunicação ubíqua: repercussões na cultura e na educação. São Paulo: Paulus, 2013.

SHARPLES, M.; TAYLOR, J.; VAVOULA, G. A theory of learning for the mobile age. In: Medienbildung in neuen Kulturräumen. Kassel, Alemanha: VS Verlag für Sozialwissenschaften, 2010. p. 87-99.

SOUSA, E; MARQUES, E. 0 processo de constituir-se professor na relação objetividade--subjetividade: significações acerca da mediação social na escolha pela docência. Educação \& Formação, Fortaleza, v. 4, n. 11, p. 82-96, 2019. Disponível em: https://revistas.uece.br/index.php/redufor/article/view/841/1143. Acesso em: 23 maio 2019.

THERRIEN, J.; AZEVEDO, M. R.; LACERDA, C. A racionalidade pedagógica nos processos de mediação à produção de sentidos e de aprendizagem aos saberes. Educação \& Formação, Fortaleza, v. 2, n. 6 , p. 186-199, 2017. Disponivel em: https://revistas.uece.br/index.php/redufor/article/view/166. Acesso em: 23 maio 2019.

TRIGUERO, I. M. G. Gamificación y tecnologías como recursos y estrategias innovadores para la enseñanza y aprendizaje de la historia. Educação \& Formação, Fortaleza, v. 3, n. 8, p. 3-16, 2018. Disponivel em: https://revistas.uece.br/index.php/redufor/article/view/267/195. Acesso em: 10 jan. 2019.

UNESCO. 0 Futuro da aprendizagem móvel: implicações para planejadores e gestores de políticas. Brasilia: UNESC0, 2014. 64 p.

VEIGA, I. P. A. Docência: Uma construção ético-profissional. Campinas: Papirus, 2005. 
VIEIRA, V.; BIANCONI, M. L.; DIAS, M. Espaços não-formais de ensino e o currículo de Ciências. Ciência e Cultura, Campinas, v. 57, n. 4, p. 21-23, 2005.

WU, W. et al. Review of trends from mobile learning studies: A meta-analysis. Computers \& Education, Washington, v. 59, n. 2, 2012, 817-827.

ZABALA, A. A prática educativa: como ensinar. Porto Alegre: Artmed, 1998.

ZURITA, G.; NUSSBAUM, M. A conceptual framework based on activity theory for mobile CSCL. British Journal of Educational Technology, Londres, v. 38, n. 2, p. 211-235, 2007.

Endereço para correspondência: Centro Universitário Christus - Unichristus, Campus Parque Ecológico, Rua João Adolfo Gurgel, 133 - Cocó, 60190-180, Fortaleza, Ceará, Brasil.

Roteiro, Joaçaba, U. 45, p. 1-24, jan./dez. 2020 | e23002 |E-ISSN 2177-6059 